\title{
1. Learning from death
}

We were at the Coroner's Court so New Zealand could learn from Adam's death. We did not want Adam's life to be a waste. ${ }^{1}$

The inquest at least gave us some answers to our questions about how the pregnancy was managed and the death of our baby daughter Ava Mae. . Hopefully the verdict of HM Coroner will be taken to heart and acted upon by the hospital so that other parents will be spared the pain and emotional turmoil that we have had to endure simply to discover the truth about why our little baby girl's life was

so short. ${ }^{2}$

\subsection{INTRODUCTION}

In February 2011, in a New Zealand (NZ) coronial inquiry that attracted widespread media attention, Robert Barlow, father of the deceased baby, Adam, explained: ${ }^{3}$

We don't want our son to be remembered as the baby who died at the hands of a flawed maternity system. We want him to be remembered as the baby who brought about positive change in the maternity sector for the good of future mothers and babies.

Coroner Matenga found that baby Adam died after a "series of failures" by the midwife contributed to a hypoxic intrauterine environment during a prolonged second stage of labour due to foetal malposition. ${ }^{4}$ During the

1 Interview with Robert Barlow (Jennifer Moore, 11 October 2012). Participants could elect to be named or anonymous. Pseudonyms are used throughout this book for all coroners, apart from the then Chief Coroner, who chose to be named. Those organisations and interested parties who elected to remain anonymous have been given pseudonyms.

2 "Baby Born Alive 'Wrongly' Recorded as Stillborn" The Telegraph (31 October 2012). <http://www.telegraph.co.uk/health/healthnews/9646068/Babyborn-alive-wrongly-recorded-as-stillborn.html>.

3 Barlow [2012] NZCorC 87.

4 Barlow, above n 3; Maryanne Twentyman "Midwife rejects baby death ruling” Stuff (New Zealand, 9 May 2012). 
pregnancy, Linda Barlow (Adam's mother) had conveyed her concern about her baby's posterior position to her midwife. Adam's parents felt that the care they received from the midwife who looked after Linda at the time of Adam's birth had contributed to the death of their son.

The Barlows' experience began in 2008 when they relocated to NZ from the United Kingdom (UK). In an interview with me, Robert described their decision-making: ${ }^{5}$

We felt that it would be a better place for our children to grow up, which is a bit ironic. There are good things about maternity here and over there [the UK]. The system we have here [in NZ] was put into place 20 years ago and there has been no review to see whether it is working. In Hamilton there are no obstetricians anymore. I think there should be a choice for people.

In NZ, Linda became pregnant with baby Adam. On 24 October 2009, Linda's waters broke and her contractions began. The Barlows met their midwife at River Ridge East Birth Centre, in Hamilton, NZ. The midwife assessed Linda as being in early labour and she was sent home, despite her wanting to remain at River Ridge. Linda became fully dilated at home and an ambulance returned her to River Ridge. Because of a lack of progress in labour, Linda was transferred to Waikato Hospital.

The midwife did not communicate any urgency to the hospital midwives regarding the labour and little clinical information was provided. There was confusion about whether the responsibility for primary care remained with the midwife or the hospital midwives. After complaining of not being able to breathe, Linda was rushed to theatre for an emergency caesarean section. Adam was born by emergency caesarean section at $3.00 \mathrm{pm}$ and died shortly after birth.

In his findings, Coroner Matenga considered the procedural issue of jurisdiction. ${ }^{6}$ NZ, English and Australian coroners do not have jurisdiction to investigate stillbirths. ${ }^{7}$ Despite the paediatrician's conclusion that Adam was stillborn, the coroner received evidence that Adam had been assessed by nurses as having a faint heart beat when born. This is a sign of life and, therefore, Adam could not be classed as a stillborn child. The coroner concluded he had jurisdiction to open an inquiry. ${ }^{8}$

During the inquest, an obstetrician who gave expert evidence described

Barlow, above n 1.

Barlow [2012] NZCorC 87.

7 Ian Freckelton "Stillbirth and the Law: Options for Law Reform and Issues for the Coronial Jurisdiction” (2013) 21 JLM 7; Coroners Act 2006 (NZ) s 9.

8 Barlow [2012] NZCorC 87. 
Adam's death as "needless" and stated that Mrs Barlow had experienced "gross neglect in labour". ${ }^{9}$ The then NZ Minister of Health, Tony Ryall, described the case as "deeply distressing". ${ }^{10}$ In 2012, Coroner Matenga directed three recommendations to the NZ Ministry of Health, one recommendation to the Waikato District Health Board and five recommendations to the Midwifery Council of NZ. ${ }^{11}$

After the tragic death of their baby, the Barlows hoped that the lessons from their experience would prevent similar deaths. In my interview with Robert, he explained that he and Linda viewed the coronial process, especially the coroner's recommendations, as a way to achieve this goal and to ensure that Adam's life was not a "waste". ${ }^{12}$

Coroners in NZ can make recommendations that may reduce the chances of occurrence of similar deaths in the future. ${ }^{13}$ Likewise, coroners in many other jurisdictions (such as England, Australia and Canada) may make public health and safety recommendations. ${ }^{14}$ Like the Barlows, a common refrain of those who have lost family members to preventable death is that they want the coronial system to ensure that "this doesn't happen to anyone else". ${ }^{15}$ Many NZ families believe and hope that coroners" findings and recommendations can "make a massive difference to saving people's lives". ${ }^{16}$

Similarly, families in many other parts of the world hope that coroners' findings will save other people's lives in the future, so that other families "will be spared the pain and emotional turmoil that [they] have had to endure". ${ }^{17} \mathrm{Mr}$ and Mrs Charlton made this comment after the tragic death of their baby daughter, Ava Mae. Ava Mae Charlton was born in England in September 2009, but died shortly after she was born, following a delayed emergency caesarean. Ava Mae's death was recorded as a

9 Barlow, above n 3.

10 Twentyman, above $\mathrm{n} 4$.

11 Barlow, above n 3.

12 Barlow, above $\mathrm{n} 1$.

13 Coroners Act 2006 (NZ) s 3(1)(b).

14 For example, see the Coroners Act 1985 (Vic, Australia) s 19(2); Coroners Act 1997 (ACT, Australia) s 52(4); Coroners Act RSO 1990 (Ontario, Canada) c C-37, s 313(3); Coroners (Amendment) Rules 2008 (England and Wales) Rule 43.

15 Cliff Taylor "Toxic gas death inquiry" The New Zealand Herald (Auckland, 15 June 2008).

16 Kim Thomas "Call for wider licence review powers" Stuff (New Zealand, 25 February 2009).

17 "Baby born alive wrongly recorded as stillborn" The Telegraph (London, 31 October 2012). 
stillbirth. The distraught parents fought for two years to get their baby's death investigated. The mother, Mrs Charlton, explained that the inquest "at least gave us some answers to our questions about how the pregnancy was managed and the death of our baby daughter Ava Mae". ${ }^{18}$ Like NZ families, this English family also wants coronial inquiries to be the catalyst for change. Their wish - that we can learn from death - is at the heart of this book.

For many organisations that receive coroners' recommendations, it is important that their health and safety messages are aligned with the coronial preventive purpose. They, too, are motivated by a desire to prevent fatalities. According to the NZ Electricity Engineers' Association: ${ }^{19}$

Everybody is really interested in this research and the Government's review ... because what coroners say, and dealing with their recommendations, is actually really important in terms of how we run our business and how we run our industry.

Coronial information is of particular importance to policymakers, organisations, practitioners and researchers who have an interest in mortality and morbidity prevention. Many organisations analyse coroners' recommendations for patterns, so that these trends can inform, and improve, their work. However, adverse comments in coronial recommendations can cause reputational harm to organisations. It is unsurprising, then, that coroners' recommendations have an important impact on the way that businesses and industries are managed.

The public interest in coroners' recommendations can be demonstrated by the frequency of media items about coronial inquiries. This research generated widespread media attention. On 18 July 2014, there were 23 media items about this project. ${ }^{20}$ The coroners interviewed for this study commented that the media play an important role in publicising the health and safety messages in coronial recommendations.

18 "Baby born alive wrongly recorded as stillborn" The Telegraph (London, 31 October 2012).

19 Interview with Electricity Engineers' Association (Jennifer Moore, 7 February 2013).

20 For example, see Vaimoana Tapaleao "Findings by Coroners Fall on Deaf Ears" The New Zealand Herald (Auckland, 18 July 2014); David Loughrey "Chief Coroner Welcomes Study" Otago Daily Times (Dunedin, 18 July 2014); Collette Devlin and Tessa Johnstone "Report Highlights Failings of Coronial System" Dominion Post (Wellington, 18 July 2014). 
However, not all media coverage of the Coronial Services of NZ (CSNZ) is favourable. For example, Sir Bob Jones (a NZ property developer) expressed his frustration about the quality of coronial recommendations by issuing his own recommendations for coroners. Specifically, he asserted that: ${ }^{21}$

At the next coroners' annual conference, instead of speeches they should have half a dozen ex-All Black forwards present to line them up, bend them over and render hourly bum-kicking sessions which hopefully will bring them to their senses.

This comment was primarily prompted by a coronial finding about the death of a woman from cardiac arrhythmia, which was attributed, in part, to her excessive consumption of Coca-Cola. ${ }^{22}$ The coroner found that the woman's consumption of six to ten litres of Coca-Cola per day was a substantial contributor to the development of the imbalances that caused her arrhythmia. The coroner made recommendations to the NZ Ministry of Health and Coca-Cola:

To: The Ministry of Health

I. That it be considered, in consultation with ESR and other appropriate experts, whether, in light of the evidence given to the Inquest Hearing, that the warning labels on carbonated beverages give sufficient protection to consumers. The hazards to the health of the consumers of excessive quantities of sugar and caffeine contained in carbonated beverages could be more clearly emphasised.

II. It is noted that the caffeine content for "formulated caffeine beverages" defined as those containing 145 milligrams/L or more (Standard 2.6.4), is regulated. Consideration could be given to either the lowering of the caffeine percentage limit or creating a more specific warning such as those printed on cans containing "formulated caffeine beverages," produced and marketed by Coca-Cola. It may also be considered appropriate to review standard 2.6.4 to reduce the caffeine content threshold to enable more specific advice to consumers to be given.

To: The Coco-Cola Company - Coca-Cola Amital (NZ) Limited, Coca-Cola Oceania Limited

21 Bob Jones "Bob Jones: Coroners should shut up and do their jobs" The New Zealand Herald (Auckland, 19 February 2013).

22 Harris [2013] NZCorC 46. 
I. That consideration is given to the inclusion of advice as to the quantity of caffeine on the labels to its products and of the adding to the labels appropriate warnings related to the dangers of consuming excessive quantities of the products.

These coronial recommendations not only generated media comment from Sir Bob Jones, but also from Michael Laws (a NZ writer, broadcaster and politician). Laws asserted that the deceased's "stupid" lifestyle choices caused her cardiac arrhythmia. ${ }^{23} \mathrm{He}$ also argued that: ${ }^{24}$

The problem with this new breed of coroners created by the 2006 Coroners Act [is that] they are becoming increasingly draconian in their recommendations linking one odd death or one accidental fatality to some kind of systemic failing in our society.

In keeping with Laws' complaints, a commonly cited weakness of coroners' recommendations is that they focus on an isolated case. There has been a tendency for some coroners to extrapolate a generic recommendation based on an individual case (or in some instances, grouped clusters of cases). In their critiques of the coroner's recommendations about Coca-Cola, many other commentators similarly focused on the limitations of using a single case to inform recommendations. One commentator contended that coroners "ignore the extreme oddity of the circumstances and ascribe them to the community at large" and "too often fail to recognise freak accidents as simply that, namely freak". ${ }^{25}$

In contrast to these views, Professor Sellman of the National Addiction Centre at the University of Otago in NZ supported the coroner's recommendations and advocated for an overhaul of food labelling in NZ. ${ }^{26}$ Recent public health research demonstrates that the proposed overhaul of food labelling in NZ has support from industry, policymakers and nongovernment organisations. ${ }^{27}$

23 Michael Laws "Individual Stupidity No Reason to Curb Our Freedoms" Sunday Star Times (17 February 2013) A11.

24 Laws, above $n 23$.

25 Cameron Slater "Bob Jones on Idiot Coroners, They Deserve a Good Bum Kicking” (21 February 2013) Whale Oil Beef Hooked <http://www.whaleoil.co.nz/ tag/natasha-harris/>.

26 TVNZ "Professor backs coded food labels after Coca-Cola death - National News | TVNZ" (14 February 2013) TVNZ <http://tvnz.co.nz/national-news/ professor-backs-coded-food-labels-after-coca-cola-death-5341540>.

27 Louise Signal and others "Front-of-pack Nutrition Labelling of Food in New Zealand: An Exploration of Stakeholder Views about Research and Implementation" (2012) 23 Health Promotion Journal of Australia 48. 
In this context of apparent controversy about coronial inquiries, I embarked upon exploration of the veracity of commentators' assertions about coroners' recommendations. In particular, my research is concerned with providing evidence-based answers to four overarching questions: (1) What is the nature of coronial recommendations? (2) Who are the recipients of coroners' recommendations? (3) Is NZ's coronial law achieving its full preventive potential? and (4) Should a regime requiring responses to coroners' recommendations be part of $\mathrm{NZ}$ law?

Described as "the ombudsman for the dead", 28 the coroner's role is to identify the causes and circumstances of sudden or unexplained deaths, or deaths in special circumstances, such as deaths of people under compulsory detention. Coronial death investigations cover deaths in widely varying circumstances, from deaths as a result of criminal activity, missing persons who are suspected to have died, and deaths that occur in the course of clinical care. The coroner may hold an inquiry into a death to determine the deceased's identity, and when, where, how and why s/he died. ${ }^{29}$ The coroner makes decisions about whether to order a postmortem and whether to retain or release body parts and tissue samples.

Not all deaths reported to the coroner result in an investigation or inquiry. In 2010, the NZ Coroner's Office had 5645 deaths reported where there was uncertainty as to whether a medical certificate of the cause of death could be issued. ${ }^{30}$ The coroner accepted jurisdiction in respect of 3343 of those cases. In the remaining 2302 cases, the coroner and doctor discussed the case and a medical certificate of cause of death was issued rather than commencing a coronial investigation. In practical terms the coroner will usually discuss the death with the consultant and make a judgement call whether the case warrants investigation.

If a coroner undertakes an inquiry (either by inquest or in chambers), $\mathrm{s} / \mathrm{he}$ is not required to make recommendations or comments to prevent the occurrence of future similar deaths. If a coroner does make recommendations, a copy of the findings (including the recommendations) is sent to the organisation/s stated in the coroner's decisions to those entities by the coroner's administrative staff. When a NZ coroner directs a recommendation to an organisation, there is no statutory requirement for that organisation to respond to the coroner (or any entity) about what, if any-

28 R.C. Bennett "The Changing Role of the Coroner" (1978) 118 CMA 1133 at 1133 .

29 Coroners Act 2006, s 4(2).

30 Email from CSNZ to Jennifer Moore regarding number of deaths in the coronial jurisdiction (2 February 2011). 
thing, they propose to do. However, some organisations do voluntarily write letters in response to coroners' recommendations. Those responses are often described in the CSNZ Recommendations Recap. ${ }^{31}$

NZ's recent disasters, such as Pike River and the Christchurch earthquakes, have brought mortality into focus. ${ }^{32}$ There are approximately 29000 deaths in NZ per year. ${ }^{33}$ About $20 \%$ of those deaths must be reported to the coroner. ${ }^{34}$ According to John Fogarty QC, "there can be no doubt that the Coroners Act saves lives, and establishes a process whereby the community can have confidence of an independent inquiry into unusual death where no one ... can hide from scrutiny." 35

There is no NZ empirical research, and limited international research, about the extent of organisations' implementation of coroners' recommendations. A recent Australian study explored the implementation of coroners' recommendations in Victoria. ${ }^{36}$ This book is the first NZ project to investigate the rigour of coronial recommendations, and the extent of their impact and implementation. The findings have informed the debate about whether law reform is required to enable coroners to fulfil their statutory prophylactic function. An evaluation of whether coroners' findings have the potential to save lives is lacking and is well overdue.

This book uses NZ data, but it has international dimensions because it also includes analysis of literature, Coroner's Court findings and appellate litigation from jurisdictions such as England, Canada, Australia and Scotland. In the next section, I explore the literature from around the world that has examined the coronial jurisdiction.

31 Coronial Services of New Zealand "Recommendations Recap - Coroners Court" Coronial Services of New Zealand <http://www.justice.govt.nz/courts/ coroners-court/publications/recommendations-recap $>$.

32 "Christchurch earthquake" Stuff (New Zealand, 22 February 2012); "Pike River: Our darkest hour" Stuff (New Zealand, 24 November 2012).

33 Statistics New Zealand Births and Deaths (2012).

34 Sue Johnson "Births, Deaths and Coroners' Inquiries" in Health Care and the Law (4th ed., Brookers, Wellington, 2010).

35 John Fogarty "A Chief Coroner" [2000] NZLJ 316 at 316.

36 Georgina Sutherland and others "What Happens to Coroners' Recommendations for Improving Public Health and Safety? Organisational Responses Under a Mandatory Response Regime in Victoria, Australia” (2014) 14 BMC Public Health 732. 


\subsection{RESEARCH ON CORONERS AND CORONERS' RECOMMENDATIONS}

Given the high public profile of coroners, it is surprising that little is known about coroners' decision-making or their recommendations. Numerous scholars have observed that the work of coroners remains largely under-researched. ${ }^{37}$ For instance, Bugeja and Ranson observe that despite the "significance of coroners' recommendations for public health and safety, they are a relatively unexplored area of socio-legal and medico-legal research". ${ }^{38}$ In 2006, in their authoritative text on coronial law, Freckelton and Ranson noted that it is "remarkable that no empirical base" has yet been generated. ${ }^{39}$ There is limited empirical research about the formulation, nature, purpose and implementation of coroners' recommendations.

Empirical research about coroners, their procedures and recommendations is recent. Research in Australia and the UK has quantified the frequency of coroners' recommendations, ${ }^{40}$ investigated coronial inquiries about healthcare-related deaths, ${ }^{41}$ conducted case studies on specific categories of death, ${ }^{42}$ and provided legal and forensic descriptions of death investigations. ${ }^{43}$ A 2011 NZ LLB(Hons)

37 For example, see Susanne Langer, Jonathan Scourfield and Ben Fincham "Documenting the Quick and the Dead: A Study of Suicide Case Files in a Coroner's Office" (2008) 56 The Sociological Review 293 at 294; Ian Freckelton and David Ranson Death Investigation and the Coroner's Inquest (Oxford University Press, Melbourne, 2006); Ray Watterson, Penny Brown and John McKenzie "Coronial Recommendations and the Prevention of Indigenous Death" (2008) 12 Special Edition 2 Australian Indigenous Law Review 4; David Studdert and Stephen Cordner "Impact of Coronial Investigations on Manner and Cause of Death Determinations in Australia, 2000-2007" (2010) 192 MJA 444.

38 Lyndal Bugeja and David Ranson “Coroners' Recommendations: Do They Lead to Positive Public Health Outcomes?" (2003) 10 JLM 399 at 399.

39 Freckelton and Ranson, above n 37, at 742.

40 Lyndal Bugeja "Determinants of Coroners' Recommendations on External Cause Deaths in Victoria, Australia" (PhD, Monash University, 2011); Bugeja and others "Application of a Public Health Framework to Examine the Characteristics of Coroners' Recommendations for Injury Prevention" [2012] 18 Injury Prevention 326.

41 Carol Grech "Coronial Inquiries into Fatal Adverse Events in South Australian Hospitals: From Inquest to Practice" (PhD, The University of Adelaide, 2004).

42 Boronia Halstead Coroners' Recommendations and the Prevention of Deaths in Custody: A Victorian Case Study (1995).

43 Freckelton and Ranson, above n 37. 
thesis explored coronial recommendations, but it was not empirical research. ${ }^{44}$

The University of Melbourne's Public Health Law group recently published their first article about research on the introduction of Victoria's mandatory response regime for coronial recommendations. ${ }^{45}$ Despite speculative commentary about organisations' responses to coroners' recommendations, there is limited empirical research about the extent of implementation of coronial recommendations. Prior to the Melbourne study, in 2008, Watterson et al. sent letters to several hundred organisations, located in every Australian jurisdiction except Queensland, following their receipt of coroners' recommendations, to inquire how they had responded. ${ }^{46}$

Queensland, the state omitted from the Watterson et al. study, undertook its own review of organisations' responses to coroners' recommendations in 2006. ${ }^{47}$ This review focused on recommendations made to public sector agencies. The review found a relatively high rate of implementation ( $68 \%$ fully or partially implemented), but there was no distinction made between action taken before or after recommendations were handed down. The review outlined the main reasons for rejection: concerns that recommendations were too costly, inappropriate or unrealistic, or not within the organisation's power to implement. This Queensland study, the Melbourne research and my NZ project endeavour to tackle "the greatest challenge that remains, [which] is to understand the reasons for the apparent low implementation rate of coroners' recommendations, despite repeated instances of similar fatalities". ${ }^{48}$

Social scientists have undertaken empirical analyses of coronial work. Atkinson's classic 1970s research explored the social organisation of sudden death. ${ }^{49}$ More recently, Timmermans has examined the professional authority of medical examiners' determinations on suicide and undertaken ethnography research in a medical examiner's

44 Kate Tidbury "Coronial Recommendations: Ensuring the Dead Really do Speak to Protect the Living" (LLB(Hons), Auckland University, 2011).

45 Sutherland and others, above $\mathrm{n} 36$.

46 Watterson, Brown and McKenzie, above n 37.

47 Queensland Ombudsman The Coronial Recommendations Project: An Investigation into the Administrative Practice of Queensland Public Sector Agencies in Assisting Coronial Inquiries and Responding to Coronial Recommendations (2006).

48 Bugeja, above n 40.

49 Maxwell Atkinson Discovering Suicide: Studies in the Social Organization of Sudden Death (MacMillan, London, 1978). 
office. ${ }^{50}$ Social scientists have also analysed families' experiences of inquests ${ }^{51}$ and how coroners' decisions classify natural versus unnatural death. ${ }^{52}$

There is much non-empirical commentary about coroners, their work and recommendations. ${ }^{53}$ An Australian, Professor Ian Freckelton QC, is one of the most prolific scholars of coronial law. ${ }^{54}$ Coroner or medical examiner information has also been used as the primary data source for descriptive and analytic research to examine and report the nature, extent, determinants and interventions for the prevention of external-cause deaths. ${ }^{55}$ Coronial records have also been used for historical research about suicides in NZ. ${ }^{56}$

50 Stefan Timmermans Post Mortem: How Medical Examiners Explain Suspicious Deaths (University of Chicago Press, Chicago, 2007); Stefan Timmermans "Suicide Determination and the Professional Authority of Medical Examiners" (2005) 70 American Sociological Review 311.

51 Lucy Biddle "Public Hazards or Private Tragedies? An Exploratory Study of the Effect of Coroners' Procedures on Those Bereaved by Suicide" (2003) 56 Social Science and Medicine 1033.

52 Lindsay Prior "The Good, the Bad and the Unnatural: A Study of Coroners' Decisions in Northern Ireland" (1985) 33 Sociological Review 64.

53 Justin Malbon "Institutional Responses to Coronial Recommendations" (1998) 6 JLM 35; Hugh Selby The Inquest Handbook (The Federation Press, Sydney, 1998).

54 For example, see Ian Freckelton "Anglo-Australian Coronial Law Reform: The Widening Gap" (2010) 17 JLM 471; Ian Freckelton "Coronership Under Challenge: The Evolving Institution of the Modern Coroner" (The Greek Legal and Medical Conference, Corfu, Greece, 2009); Ian Freckelton "Reforming Coronership: International Perspectives and Contemporary Developments" (2008) 16 JLM 379; Ian Freckelton "The Myers Oration 2005: Untimely Death, Law and Suicidality" (2005) 12 Psychiatry, Psychology and Law 265; Ian Freckelton "International Trends in Death Investigation" (World Association of Medical Law Conference, Brazil, 8 August 2012); Freckelton and Ranson, above n 37; Ian Freckelton "Death Investigation and the Evolving Role of the Coroner" (2008) 11 Otago LR 565; Ian Freckelton "Death Investigation, the Coroner and Therapeutic Jurisprudence" (2007) 15 JLM 242.

55 For example, see Randy Hanzlick "The Role of Medical Examiners and Coroners in Public Health Surveillance and Epidemiologic Research" (1996) 17 Annual Review of Public Health 383.

56 John Weaver Sorrows of a Century: Interpreting Suicide in New Zealand, 1900-2000 (Bridget Williams Books and McGill-Queen's University Press, Wellington and Montreal, 2014). 


\subsection{RESEARCH AIMS, OBJECTIVES AND SIGNIFICANCE}

This research, the first of its kind in NZ, aimed to describe, quantify and investigate the nature, recipients and preventive potential of NZ coroners' recommendations from 1 July 2007 to 30 June 2012. 1 July 2007 was chosen as the commencement date because that is when the Coroners Act 2006 (NZ) came into force.

Quantifying the number of recommendations for my five-year study period was a useful aim in itself. On the basis of estimates provided by the CSNZ, my 2012 research proposal estimated that my study period would include approximately 1060 recommendations. My research findings aimed to provide an exact quantification of the number of recommendations for my study period.

Identifying and interviewing the recipients of coroners' recommendations during my study period was a useful objective. I needed to identify the recipients of recommendations in order to examine their rate of implementation. The most prevalent concern is that coroners' recommendations are ineffective because the organisations to which they are directed ignore them. ${ }^{57}$ My research assessed the veracity of this concern.

My project also aimed to investigate the preventive potential of coronial recommendations. Coroners spend time making recommendations, and considerable financial resources are spent on public inquests and the administration of the NZ Act. The NZ Ministry of Justice spent $\$ 16.57$ million to administer the Act in 2010/11. ${ }^{58}$ The outlay of funds is justified, partly, on the basis that coroners' recommendations contribute to preventive public health goals. Yet, no research had assessed the public health impact of coroners' recommendations. Is the preventive purpose of the Act being achieved? How can coroners' statutory roles as "public health officials" be effectively fulfilled? ${ }^{59}$ A key purpose of my research was to provide evidence-based answers to these questions.

Additional research aims were to:

- analyse the rigour of coronial recommendations

- explore the relationship between coroners' recommendations and morbidity and mortality prevention

\footnotetext{
57 Sutherland and others, above $\mathrm{n} 36$.

58 Email from CSNZ to Jennifer Moore regarding cost to administer the Coroners Act 2006 (2 August 2011).

59 Freckelton, above n 54, at 244.
} 
- analyse what improvements, if any, are required to maximise the preventive potential of coroners' recommendations

- examine the factors that affect the implementation of coronial recommendations

- provide an exploratory project to a field which is important, yet under-researched

- contribute to coronial practice and provide feedback to the CSNZ

- inform law reform, particularly about whether a mandatory response regime should be introduced in NZ.

The research objectives were to:

1. Analyse NZ coroners' recommendations from 2007 to 2012.

2. Conduct semi-structured interviews with coroners, recipients of recommendations and interested parties.

3. Survey recipients of recommendations who received coroners' recommendations during the study period and who were not interviewed.

4. Analyse appellate litigation about coroners' recommendations and their preventive function.

As Pickering has commented, studying practices (as this project does) can contribute to the "development of critical and policy-oriented perspectives". ${ }^{60}$ My purpose was to bridge the research-practice and research-policy divides. Such research-practice translation includes feedback to research participants. Twelve of the fifteen coroners I interviewed reported that they are largely unaware of their colleagues' practices. One coroner explained that he "doesn't talk as freely . . . to my fellow coroners as I am to you [the interviewer]" and that he "would love to see, to know, more about how other coroners do their work". ${ }^{61}$ This research seeks to provide some insight into coronial practice, particularly their decisionmaking about recommendations.

60 Andrew Pickering "From Science as Knowledge to Science as Practice" in Science as Practice and Culture (University of Chicago Press, Chicago and London, 1992) 1 at 6.

61 Interview with Coroner Dymond (Jennifer Moore, 16 October 2012). 


\subsection{STUDY METHODS AND UNDER-REPORTING IN THE NZ CORONIAL JURISDICTION}

While the topic of this book is legal, I use methods from public health and health sociology. ${ }^{62}$ The research questions cannot be answered using legal methods alone. As Freckelton and Ranson have pointed out, it is "unlikely that the available data sets will be mined in a way that their potential would allow ... unless specialists in epidemiological analysis [public health researchers] are employed by Coroner's offices on a regular basis". 63

This book is based on the following data:

1. coroners' recommendations

2. interview transcripts

3. questionnaire responses

4. appellate decisions.

\subsubsection{Coroners' Recommendations}

The aims of the textual analysis of coroners' recommendations were to describe the:

- nature of NZ coroners' recommendations

- nature of the recipients of coroners' recommendations.

The study population comprised deaths reported to, and investigated by, the CSNZ for the five-year study period 1 July 2007 - 30 June 2012, where one or more recommendations were made by coroners in their findings. A coroner's finding is a report written by the coroner about the facts of a death. The finding will include who the deceased was, where, when, and how s/he died. The finding is a public document. Members of the public can request copies, although there may be prohibition orders.

Comments or recommendations arising from coronial investigations are usually located at the end of the finding. The recipients to be sent one or more recommendations are usually specified in the recommendation or comment itself. However, coroners differ in the way that they write their findings, the frequency that they make recommendations and the scope of

62 The author of this book is a lawyer, health scientist and social scientist with a PhD in Public Health from the University of Melbourne's Faculty of Medicine.

63 Freckelton and Ranson, above n 37, at 741. 
those recommendations. ${ }^{64}$ There is a template for NZ coronial findings, but it is not used by all coroners. The following template was proposed by Harding J ${ }^{65}$

IN THE CORONERS COURT

AT [Location]

\section{CSU-201}

UNDER

THE CORONERS ACT 2006

AND

IN THE MATTER of an Inquiry into the death of

[Name of deceased]

Date(s) of Hearing: [Date]

Appearances:

Date of Findings:

\section{FINDINGS OF CORONER [initials and surname]}

\section{INTRODUCTION}

[1] Xxx

FACTS

[2] $x x x$

\section{ISSUES}

[3] xxx

\section{DISCUSSION}

[4] xxx

\section{CONCLUSIONS}

[5] Xxx

\section{FORMAL FINDINGS}

[6] $x x x$

\section{COMMENTS/RECOMMENDATIONS}

[7] xxx

\section{RESTRICTION OF PUBLICATION}

[8] xxx Coroner [initials and surname]

64 This variation in coronial findings and recommendations is also evident in Australian states and territories. For example, see Federation of Community Legal Centres, Victoria Saving Lives by Joining up Justice: Why Australia Needs Coronial Reform and How to Achieve it (2013) at 27.

65 I am grateful to Coroner McElrea for drawing my attention to this template. 
Many researchers, particularly in public health and social science, regard coronial information as a rich source of data. ${ }^{66}$ However, it is not necessarily easy to access coronial data. Coronial websites in NZ and Australia do not provide automatic access to all coroners' findings. An Australian report concluded that "there are significant limitations to most of the publicly available information". ${ }^{67}$ The report highlights the access difficulties faced by "advocates and researchers trying to prevent future deaths ... via accessing findings and recommendations for all similar deaths" because the "information sought is often not publicly accessible via the internet". 68

Given the limitations of the coronial data sources, what coronial information was used for this study and how was it accessed? If a researcher cannot source the data from the internet, could s/he access the information from the NZ Coroner's Court Law Reports? There are no formal law reports for the NZ Coroner's Court, even though the NZ Coroner's Court is a Court of Record. ${ }^{69}$ Commentators have identified under-reporting, and the undesirable consequences such as inconsistent decision-making, as problematic for the coronial jurisdiction. ${ }^{70}$

Without the extremely helpful and competent assistance of the then NZ Chief Coroner and the CSNZ staff, this research would not have been possible. ${ }^{71}$ With their assistance, the information for this study was available from four sources:

1. the CSNZ and their case management system (CMS)

2. the CSNZ website

3. New Zealand Legal Information Institute (NZLII)

4. Recommendations Recap.

66 Timothy Robert Driscoll "The Epidemiology of Work-related Fatalities in Australia" (Doctor of Philosophy, University of Sydney, 2002); Bugeja, above n 40 , at $107-8$.

67 Federation of Community Legal Centres, Victoria, above n 64, at 24.

68 At $24-5$.

69 For example, see Newton v Coroner's Court HC Christchurch CIV-2004409-2173, 7 October 2004, where it was held that the Coroner's Court is a court of record and, as such, is subject to the general rule that proceedings ought to be heard in public unless there is a strong countervailing public interest overriding the need to disseminate information.

70 For example, see Jennifer Moore "An Empirical Approach to the New Zealand Government's Review of the Coronial Jurisdiction" (2014) 21 JLM; Freckelton and Ranson, above n 37, at ch 7.

71 I am particularly grateful to Judge Neil MacLean, the Research Counsel, Jackie Andrews, Wendy Proffitt and Dean Skachill. 
I have discussed these data sources and their limitations in detail elsewhere. ${ }^{72}$ Here, I raise the issue to illustrate that the "data sources" and "data collection" phases of this study were not straightforward tasks.

Researchers can contact the CSNZ and request a search of the CMS. The CMS is a national database for NZ coronial cases. ${ }^{73}$ Information about every death reported to a coroner since 1 July 2007 is stored on the system. If the researcher requires coronial cases pre-2007, the CSNZ will need to undertake a much more complicated and time-consuming task.

Researchers can also search the National Coronial Information System (NCIS). The NCIS is a data storage and retrieval system for coronial information for Australian cases and which, from July 2013, now also includes some NZ coronial data. ${ }^{74}$ However, the full text of coroners' findings and recommendations is not publicly available from the NCIS. If a researcher wishes to access information from the NCIS, s/he must make an application to the NCIS, which is then subject to approval by the NCIS Research Committee and the Victorian Department of Justice Research Ethics Committee..$^{75} \mathrm{~A}$ fee of $\$ 1000-\$ 2750$ is payable. ${ }^{76}$ The standard online fee for universities is $\$ 2750 .{ }^{77}$ The application process can take at least two months.

Another option is for the researcher to search the CSNZ website for information. There are a small number of full coroners' findings on the CSNZ website. Thirty-eight full findings of "public interest" are available on the website. ${ }^{78}$ If the desired finding is not in this list of 38 coroners'

72 Jennifer Moore and Mark Henaghan New Zealand Coroners' Recommendations, 2007-2012 (final report) (2014) at chapter 2.

73 Coronial Services of New Zealand "Coronial data collection - Coroners Court" (14 February 2014) Coronial Services of New Zealand <http://www. justice.govt.nz/courts/coroners-court/publications/findings-recommendations-andrecords/coronial-data-collection>.

74 National Coronial Information System "About the NCIS | National Coronial Information System" (14 February 2014) National Coronial Information System NCIS < http://www.ncis.org.au/data-collection/>.

75 National Coronial Information System "How to access data? | National Coronial Information System" National Coronial Information System NCIS $<$ http://www.ncis.org.au/how-to-access-data-on-the-ncis/>.

76 Email from Joanna Cotsonis (Access Liaison Officer, NCIS) regarding fees for access to NCIS (26 July 2013).

77 Cotsonis, above n 76.

78 Coronial Services of New Zealand "Findings of public Interest - Coroners Court" Coronial Services of New Zealand <http://www.justice.govt.nz/courts/ coroners-court/media-centre/findings-of-public-interest/findings-of-publicinterest $>$. 
findings, the researcher must email the Operations Manager at the CSNZ to request the required information. ${ }^{79}$

If a researcher does not require full coronial findings, there is more information accessible. Since late 2013, it has been possible to access most coroners' recommendations (not the full findings) from 1 July 2007 on either the CSNZ website or the NZLII. ${ }^{80}$ While this is an improvement, for legal researchers and practitioners, it is not a substitute for formal law reports. For this research, I was unable to rely on NZLII or the CSNZ website because I required the full findings.

The information provided in an individual summary of a recommendation on NZLII includes:

- the name of the case

- the date of the last update of the information

- date of the finding

- "summary of recommendation"

- recommendations or comments made by the coroner.

The "summary of recommendation" is typically only a few sentences which describes information about the case such as the cause of death. The information provided on NZLII is minimal. An example of the information provided on NZLII is as follows: ${ }^{81}$

Bellingham [2009] NZCorC 6 (17 February 2009)

Last Updated: 21 May 2012

Date of Finding: 17th February 2009

\section{SUMMARY OF RECOMMENDATIONS}

Todd Stancy Bellingham, 18 years of age at the time of this tragedy on Sunday the 26th of August 2007, died as a result of multiple injuries sustained in a car crash while participating in a rally sprint event organised by the Waiuku Dirt Track Club in the Waiuku Forest on this day.

79 Coronial Services of New Zealand "Findings and Recommendations Coroners Court" Coronial Services of New Zealand <http://www.justice.govt.nz/ courts/coroners-court/publications/findings-recommendations-and-records/>.

80 NZLII "New Zealand Coroners Court Decisions" NZLII < http://www. nzlii.org/nz/cases/NZCorC/>.

81 Bellingham [2009] NZCorC 6. 


\section{RECOMMENDATIONS MADE BY CORONER BRANDT SHORTLAND}

I. The only recommendation we can suggest is irrespective of budget constraints or policy decisions, there should always be sufficient medical expertise on course to deal with the worst case scenario in any form of motor racing. Cases such as this run the risk of an overhaul of racing rules and safety procedures.

II. We take the view that an overhaul is not warranted. There needs to be better contingent medical attention for the serious crash.

It is helpful to have this information online. I could not, though, rely on such limited information. NZLII does not even state whether the inquiry was by inquest or a chambers finding. Therefore, the full coronial findings provided by the CSNZ CMS were invaluable.

I cross-checked the recommendations on NZLII against the same findings that were on the USB drive provided by the CSNZ. This crosschecking was important because sometimes NZLII referred to a coronial statement as a recommendation, whereas the original coroner's finding referred to the same statement as a comment. For example, in the Bellingham case above, is Coroner Shortland's second recommendation actually a comment? In the first recommendation Coroner Shortland states that "the only recommendation [he] can suggest is. . ." This statement suggests that he will only make one recommendation, yet NZLII lists both statements as recommendations under a heading "recommendations made by Coroner Brandt Shortland". Given that there is a difference between a recommendation and a comment, and this study's inclusion criterion is recommendations, it was vital that I did not inappropriately code a comment as a recommendation.

Researchers and members of the public can also access a document called Recommendations Recap on the CSNZ website. ${ }^{82}$ Since late 2011, the CSNZ has been publishing this document. The Recommendations Recaps, which appear every three months, are summaries of coroners' recommendations. ${ }^{83}$ The Recommendations Recap is a useful initiative, but it is not a substitute for official law reports. They are summaries of the recommendations, not the complete findings. They do not include findings in which recommendations were not made.

The data gathered comprised the variables which I have analysed in detail elsewhere, and also the free text of the coroners' recommendations

82 Recommendations Recap documents are available from the Coronial Service of New Zealand website: <http://www.justice.govt.nz/courts/coroners-court/ publications/recommendations-recap $>$.

83 See the Coronial Service of New Zealand website. 
and comments for each coronial inquiry. ${ }^{84}$ The variables were used to classify the data in Microsoft Excel. The data analysis procedure included, broadly, assessment of the:

- number of coroners' recommendations and comments

- recipients to which recommendations were directed

- organisations' responses to recommendations

- number of coroners' references to previous, similar cases.

As Bugeja has explained, the "analysis was complex as some incidents resulted in various combinations of multiple deaths, recommendations made and organisations sent recommendations". ${ }^{85}$ For instance, a coroner may direct a single recommendation to one recipient, or multiple recipients. Alternatively, a coroner may direct many recommendations to one recipient, or multiple recommendations to many different organisations.

My final estimate of the number of coroners' recommendations is different from the number generated by the CSNZ because of our different counting rules. For example, as outlined above, I classified certain coronial statements as comments, whereas the same statements were classified by the CSNZ on NZLII as recommendations. After reading the full finding for Collings, for instance, I counted one coronial statement as a recommendation and the other as a comment, whereas NZLII has coded the two statements as recommendations. ${ }^{86}$ I encountered another scenario where NZLII recorded coronial statements as comments, but they were actually recommendations. For example, NZLII used a heading "comments made by coroner" but when I read the comments I discovered that one or more was actually a recommendation. In Keenan, for example, NZLII states "comments made by Coroner RG McElrea" and goes on to note these comments as: ${ }^{87}$

It is likely that, although the neoprene chest waders Mr Keenan was wearing are designed to give buoyancy, his chances of survival would have been enhanced if he had been wearing an inflatable life vest, preferably in conjunction with a belt. Water Safety New Zealand (WSNZ) recommends the use of neoprene chest waders. These should be worn with a belt and personal floatation device. We recommend that $W S N Z$ gives publicity to the desirability of using neoprene chest waders in conjunction with a belt and personal floatation device, by suitable publicity to members of the public and specialist suppliers and users of such products.

\footnotetext{
84 Moore and Henaghan, above $\mathrm{n} 72$ at chapter 2.

85 Bugeja, above n 40, at 201.

86 Collings [2009] NZCorC 163.

87 Keenan [2010] NZCorC 6 (author's emphasis).
} 
When one reads these supposed coronial comments, it is not difficult to notice that the coroner makes a recommendation when he states: "we recommend that WSNZ. ..." In these scenarios, I coded the appropriate comments as recommendations, ignoring the headings on the NZLII. Presumably, however, the CSNZ and the NZLII have counted these coronial statements as comments, thereby generating further differences between my quantification of coroners' recommendations and theirs.

Also, sometimes coroners' findings do not specify whether their statements are comments or recommendations. In this scenario, I coded these according to the statutory definition and the definitions of comment and recommendation described during interviews with the coroners.

The total number, range and average number of recommendations and comments per inquiry during the study period were calculated. The number and proportion of recipients to which recommendations were directed during the study period was calculated. The types of recipients sent coroners' recommendations were also described by calculating the proportion of government, not-for-profit, for-profit, individual and untargeted recipients. The number of organisations' responses to recommendations was also calculated. The data analysis also included description of the following:

- the method of case completion, by calculating the proportion of inquest or chambers inquiries

- the classification of types of deaths, by calculating the proportion of ICD-10 external cause and natural cause deaths

- the number of comments per incident

- the number of recommendations and comments per coroner

- the number of recommendations per year for the five-year study period.

After much of the data analysis of the coroners' recommendations component of the research was completed, I began the interviews.

\subsubsection{Interviews}

I interviewed 15 coroners, 79 organisations and 8 interested parties. Overall, 17 coroners were approached and 15 agreed to participate. The response rate for all coroners is $88 \%{ }^{88}$

88 A study in Victoria, Australia which included interviews of coroners had a response rate of 29.3\%. See Bugeja, above n 40, at 294 . 
Table 1.1 Recipients of coroners' recommendations, by category, NZ, 1 July 2007 - 30 June 2012

\begin{tabular}{lrc}
\hline Recipients & $\mathrm{n}$ & $\%$ \\
\hline Government & 121 & $39 \%$ \\
Not-for-profit and/or non-government & 67 & $22 \%$ \\
For-profit & 44 & $14 \%$ \\
Individuals & 5 & $2 \%$ \\
Untargeted & 72 & $23 \%$ \\
\hline
\end{tabular}

The organisations were identified from the sample of coroners' recommendations. All coroners' findings from the study sample (1 July 2007 to 30 June 2012) were read. The name/s of the recipient/s to which each coroner's recommendation was directed was entered into Microsoft Excel into a column called 'recipient'. The recipient could be single or multiple and of various types. Coroners direct their recommendations to identifiable organisations (government, not-for-profit or for-profit) or individuals. Coroners also direct their recommendations to a single recipient or multiple recipients. For instance, one recommendation can be directed to the Ministry of Health; whereas another recommendation can be directed to the Ministry of Health, the Health and Disability Commissioner, and Plunket.

Sometimes coroners direct their recommendations to groups. I coded these as 'untargeted'. This group includes recipients of recommendations where there is no identifiable organisation or individual. For instance, coroners directed recommendations to "hunters", 89 "recreational divers" 90 and "candidates for licences". 91

A dataset of 309 recipients was identified. Table 1.1 and Figure 1.1 describe the recipients of coroners' recommendations in the study sample. The highest number of recommendations were directed to government organisations $(n=121,39 \%)$. The smallest number of recommendations were directed to individuals $(n=5,2 \%)$. Although coroners "are trying to ensure that a recommendation is targeted and that it says who it is to go to", a significant proportion $(n=72,23 \%)$ were untargeted. ${ }^{92}$

89 Timms [2008] NZCorC 62.

$90 \quad$ Ngapera [2010] NZCorC 126.

91 Lewis [2011] NZCorC 186.

92 Interview with the Chief Coroner (Jennifer Moore, 12 September 2012). 


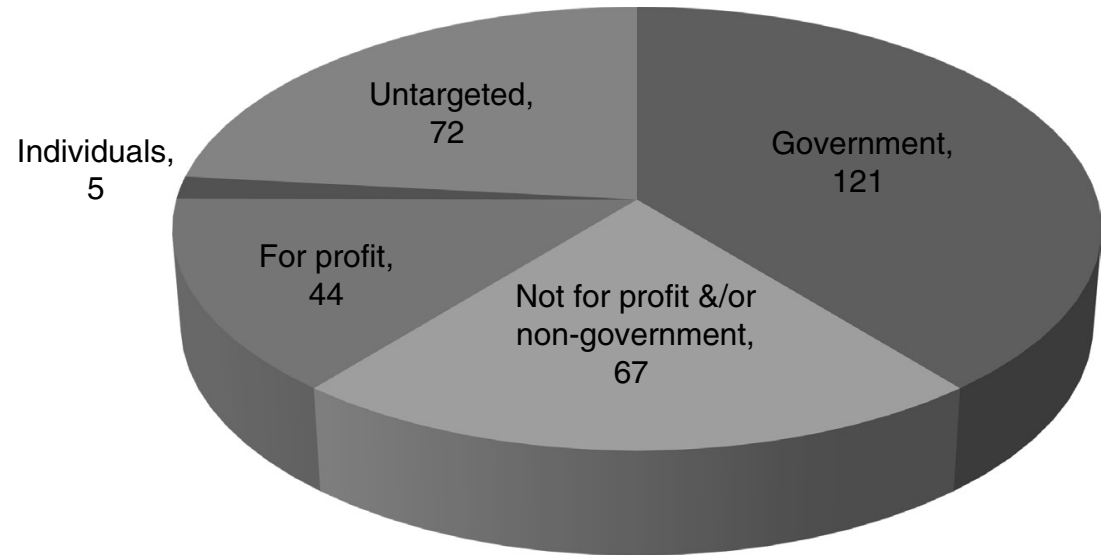

Figure 1.1 Recipients of $N Z$ coroners' recommendations

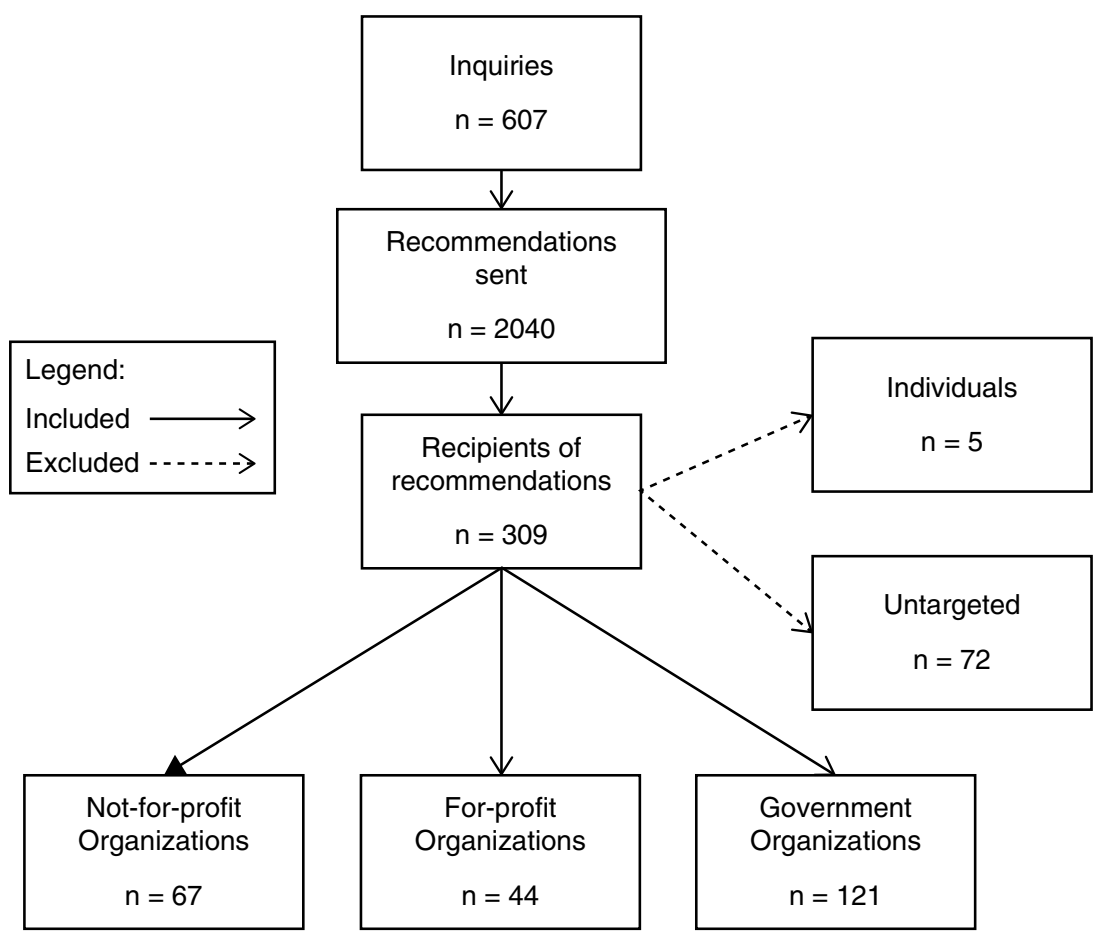

Figure 1.2 Summary of recipients of recommendations included in and excluded from the qualitative study 
Table 1.2 Number and percentage of organisations sent NZ coroners' recommendations, by type, 1 July 2007 - 30 June 2012

\begin{tabular}{lrc}
\hline Organisations & $\mathrm{n}$ & $\%$ \\
\hline Government & 121 & $52 \%$ \\
Not for profit and/or non-government & 67 & $29 \%$ \\
For profit & 44 & $19 \%$ \\
& 232 & \\
\hline
\end{tabular}

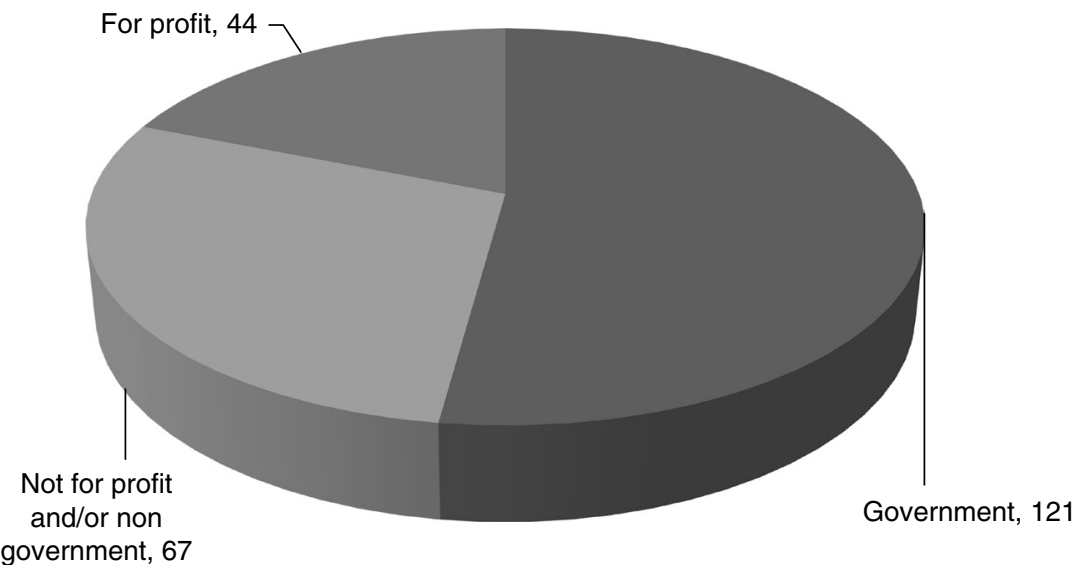

Figure 1.3 Number of organisations sent NZ coroners' recommendations, by type

Only identifiable organisations were included in the qualitative study. ${ }^{93}$ Individuals and untargeted recipients were excluded because it is not possible to contact and interview the recipients of untargeted recommendations (Figure 1.2).

The remaining dataset included 232 organisations. Table 1.2 and Figure 1.3 describe the type of organisations that were sent coroners' recommendations in the study sample. Just over half of coroners' recommendations were directed to government organisations $(n=121,52 \%)$.

The inclusion criterion was organisations that were sent coroners' recommendations during the study period. Some organisations (16)

93 Although untargeted recommendations were excluded from the qualitative study, they were included in our study of coroners' recommendations and analysed in chapter 3. 
contacted me, offering to participate. The remaining 216 organisations were contacted.

Seventy-nine of the 232 organisations were able to participate. I conducted 100 interviews with senior individuals from organisations because sometimes I interviewed more than one person from a single organisation. This is because several people are typically involved in considering coroners' recommendations. For example, at some district health boards (DHBs) it is usual for the Chief Legal Advisor, the Coronial Liaison Officer, the Chief Medical Officer, and the CEO to be involved in reviewing coroners' recommendations.

The eight interested parties include two medical professionals, three lawyers, three families and one organisation with an interest in coroners' recommendations. The sample of interested parties is not representative, nor can it be generalised to all NZ lawyers, medical professionals or families that are involved in the coronial jurisdiction. The interested parties were included because of the depth of their experience with the Coroner's Court. They also provide a different perspective on coroners' recommendations than the views garnered from organisations and coroners.

\subsubsection{Questionnaire}

As I explained in section 1.4.2 above, 79 of the 232 organisations were able to participate in the interviews. During the interviews, participants were asked for their views about the introduction of a mandatory statutory regime whereby organisations would be required to respond to coroners' recommendations. All coroners interviewed were in favour of the introduction of a mandatory response regime. Only two organisations did not support such law reform. The NZ Courts Minister's review also considered whether to include this law reform option in its review. ${ }^{94}$ The media focused on the perceived problems caused by absence of a mandatory response regime under the current Coroners Act. ${ }^{95}$

Given the public interest in this law reform option, and the strong support garnered during interviews, I decided to investigate the views of those organisations that had declined to be interviewed. I wondered

94 Cabinet Paper Coroners Act Review: Proposals for Reform-Paper 1 (2013) at [21].

95 For example, see Scott Inglis "Safety Must be Prime Concern" Bay of Plenty Times (31 January 2014) <http://www.nzherald.co.nz/bay-of-plenty-times/ news/article.cfm?c_id=1503343\&objectid=11194832 $>$ where the author argues that "coroners should be given greater powers to compel people and organisations to make changes when it comes to safety". 
whether the organisations that declined to participate in the study did not wish to be interviewed because they do not consider or respond to coroners' recommendations. I also wanted to know how many organisations that were not interviewed would agree with the introduction of a mandatory response regime for coroners' recommendations. Without the questionnaire data, a limitation of the research may have been that only those organisations that respond to coroners' recommendations participated in the study, providing unbalanced results. Combining the questionnaire data with the interview data provided a clearer picture of organisations' views about law reform options.

I devised a two-page questionnaire that asked participants (senior individuals from organisations) for their views on coroners' recommendations. The questionnaire comprised three sections. In the first section, participants were asked to respond to ten statements about coroners' recommendations using a five-point Likert scale, with 1 being 'strongly agree' and 5 being 'strongly disagree'. ${ }^{96}$ In the second section, participants were asked to state whether they believe any changes need to be made to the coronial system (yes or no option) and asked them to explain why or why not. Finally, I asked participants to explain why they did or did not support the introduction of a system which required organisations to respond to coroners' recommendations.

Forty-two of the 153 organisations returned completed questionnaires. That is a response rate of $27.4 \%$.

\subsubsection{Appellate Cases}

I reviewed appellate litigation about coroners' recommendations and the coronial preventive function. I analysed cases from NZ, Australia, Canada, England, Ireland and Scotland. The dataset included judgments over the last ten years (January 2005 - June 2015) and several significant precedents from the 1980s and 1990s. Discussion of the cases is organised thematically and, thus, appears in several sections throughout this book.

96 Research shows that a five-point scale is optimal for closed questions: Martin Tolich and Carl Davidson "Collecting Data" in Social Science Research in New Zealand (Pearson, North Shore, 2007) at 146. For further information about Likert scales, see DA de Vaus Surveys in Social Research (5th ed., Allen and Unwin, New South Wales, 2002) at 102 and 182-6. 


\subsection{STRUCTURAL OVERVIEW OF BOOK}

In Chapter 2, I explore the coronial jurisdictions in Australia, England, Scotland, Ireland, Canada, the United States and NZ. This analysis provides the context for the next chapter's discussion of coronial recommendations.

In Chapter 3, I describe and quantify the NZ coroners' recommendations in my study period. Given the limitations of the coronial information that I outline in Chapter 1, an important contribution of this study is quantifying the number of recommendations from 2007-12. The results and discussion in this chapter address my research objective to describe the nature, frequency and recipients of NZ coroners' recommendations, 1 July 2007 - 30 June 2012.

In Chapter 4 I analyse the organisations' responses to my interview questions about what action (if any) they took upon receipt of coronial recommendations and what factors influenced their decision. I explain that little is known about whether and how organisations that receive recommendations act on them. But there is much speculation that most coronial recommendations are not implemented. The most prevalent concern (expressed by coroners, public inquiries, the media and the public) is that coroners' recommendations are ineffective and have little or no preventive impact because the organisations to which they are directed ignore them. This chapter provides landmark data on the actual rate of implementation of $\mathrm{NZ}$ coronial recommendations.

Chapter 5 traces the origins of coroners' statutory prophylactic function. It also analyses the key barriers to maximising this function and strategies for improvement. This chapter highlights that the majority of research participants are supportive of the statutory preventive function. While there have been improvements since the introduction of the Coroners Act 2006 (NZ), the findings suggest that the prophylactic potential of coroners' recommendations has not yet been fully realised in NZ. The empirical evidence in this chapter suggests that recommendations could be improved by encouraging more coroners to consider similar cases, undertaking analysis of patterns and comparative risks.

The preventive potential of coroners' recommendations could also be improved by the introduction of a mandatory response regime, which is the topic of Chapter 6. I analyse the debate about whether mandatory response regimes should be included in NZ coronial legislation, drawing from overseas experiences. This chapter describes the participants' overwhelming support for the introduction of such a regime. I highlight that introduction of a mandatory response regime cannot be a replacement for early consultation with organisations and interested parties during 
the coronial process. I argue that the Coroners Act 2006 (NZ) should be amended to include a mandatory response regime and that the NZ Government's review (which excludes this proposal) is inconsistent with the empirical evidence.

Chapter 7 brings together the important threads from the preceding chapters. This chapter presents a summary of my findings, an analysis of the limitations of my research and a call for further research. It also discusses the implications of my findings and how they might inform coronial practice and law reform. 